\begin{tabular}{l|l|l|l}
$\begin{array}{c}\text { Case Reports in } \\
\text { Demillatology }\end{array}$ & $\begin{array}{l}\text { Case Rep Dermatol 2010;2:189-194 } \\
\text { DOI: 10.1159/000322963 }\end{array}$ & $\begin{array}{l}\text { Published online: } \\
\text { December 7, 2010 }\end{array}$ & $\begin{array}{l}\text { @ 2010 S. Karger AG, Basel } \\
\text { ISSN 1662-6567 } \\
\text { www.karger.com/cde }\end{array}$ \\
\hline
\end{tabular}

\title{
A Rare Case of Toxic Epidermal Necrolysis with Unexpected Fever Resulting from Dengue Virus
}

\author{
Gerrit Grieb ${ }^{a, b}$ Mastoura Alazemi ${ }^{a, c}$ Rituparna Das ${ }^{d}$ \\ Sebastian E. Dunda ${ }^{a}$ Paul C. Fuchs ${ }^{a} \quad$ Norbert Pallua $^{a}$ \\ aDepartment of Plastic Surgery and Hand Surgery, Burn Center, Medical Faculty, \\ and ${ }^{b}$ Institute of Biochemistry and Molecular Cell Biology, Medical Faculty, RWTH \\ Aachen University, Aachen, Germany; 'Al-Babtain Centre for Burns and Plastic \\ Surgery, Ibn Sina Hospital, Kuwait, Kuwait; 'Section of Infectious Disease, \\ Department of Internal Medicine, Yale School of Medicine, New Haven, Conn., \\ USA
}

\section{Key Words}

Toxic epidermal necrolysis · Dengue fever · Human immunodeficiency virus

\begin{abstract}
Toxic epidermal necrolysis (TEN), also known as Lyell's syndrome, is a life-threatening disease with common development of large wounds. Thus, affected patients are usually treated in specialized centers. Herein, we present a case of TEN in a patient infected with human immunodeficiency virus with the additional, unexpected diagnosis of dengue fever. In this context, we discuss cause, diagnosis, pathology, and treatment of TEN and highlight the role of rare and unexpected findings, as in this case an additional tropical virus infection. We underpin the importance of an interdisciplinary approach involving dermatologists, ophthalmologists, intensive care physicians, burn specialists and various other departments and emphasize the challenge of TEN treatment, especially if rare pathological findings occur.
\end{abstract}

\section{Introduction}

Toxic epidermal necrolysis (TEN) is an extreme, rapidly-evolving skin disorder, which is characterized by extensive painful cutaneous exfoliation. Also known as Lyell's syndrome, this dermatological condition can be life-threatening [1]. The major cause of TEN is medication hypersensitivity, thus the most effective treatment is the immediate withdrawal of the causative agent [2]. Due to the common development of large wounds with high risk of infection and resulting sepsis, patients suffering from TEN should be 
treated in specialized centers. Wound treatment regimens and the role of special wound dressings are still under current debate $[3,4]$. Unexpected comorbidities and pathological findings may complicate the clinical picture, making management even more challenging for burn unit teams.

In this context, we present a case of TEN in a patient infected with human immunodeficiency virus (HIV) with the additional, unexpected diagnosis of dengue fever (DF). This case report highlights the importance of clinical vigilance on the part of intensive care staff to pursue additional diagnostic considerations when patient symptoms (e.g. fever) cannot be explained by the routine causes.

\section{Case Report}

A 34-year-old African female came to the emergency room (ER) of the RWTH Aachen University, Aachen, Germany, reporting fever up to $40^{\circ} \mathrm{C}$ for a week and new painful blisters over her back and right arm with a rash over her whole body. She had a history of HIV infection for 10 years (CD4+/CD8+ ratio: 0.1; CD4+ count: 208) treated during the last year with Combivir (300 mg lamivudine and $150 \mathrm{mg}$ zidovudine p.o., 2 per day) and Kaletra (100 mg lopinavir and $25 \mathrm{mg}$ ritonavir p.o., 1 per day). After trying supportive care (vitamins and micronutrients) and pain relieving medications (500 $\mathrm{mg}$ acetylsalicylic acid p.o., 2 per day; $1 \mathrm{~g}$ acetaminophen p.o., 4 per day) for 5 days, the patient consulted a general practitioner. Concerned about a bacterial infection, he empirically prescribed cefuroxime (250 mg p.o., 2 per day) and azithromycin (500 mg p.o., 1 per day) as well as fluconazole (50 $\mathrm{mg}$ p.o., 1 per day). A rash began on her trunk the day after starting antimicrobials. It became worse the following day, expanding over the whole body with painful blisters on her back and right arm. She also developed higher fevers and malaise.

On examination by the internal ER doctor, the patient (weight: $85 \mathrm{~kg}$, BMI: 29.4) was conscious and oriented. She was normotensive (blood pressure 120/65) with sinus tachycardia (heart rate 124/min). Further examination revealed dry lips and tongue, suggesting dehydration. She had conjunctival injection, but her chest and abdominal examination revealed no abnormalities. The blisters ranged between 0.5 and $4 \mathrm{~cm}$ (fig. 1) and covered her trunk, abdomen, upper back, neck, and both arms (right more pronounced than left), covering about $45 \%$ of the total body surface area.

The ER doctor, suspecting TEN, called for the dermatologist and the burn surgeon for consultation. Confirming the presumptive diagnosis, the patient was transferred to the intensive care unit (ICU) for optimal treatment and further wound care.

On admission to the ICU, central venous access was secured and fluid resuscitation was initiated with lactated Ringer's solution. In addition to standard monitoring, central venous and arterial pressures were measured. The former antimicrobial therapy was immediately stopped. Laboratory markers revealed an increase of CRP $(201 \mathrm{mg} / \mathrm{l})$ but not leucocytes. The serum protein $(104 \mathrm{~g} / \mathrm{l})$ and the $\mathrm{LDH}$ concentration $(518 \mathrm{U} / \mathrm{ml})$ were elevated. Besides this, no pathological findings occurred. A chest $\mathrm{X}$-ray showed no pathological findings. Furthermore, cultures of blood, urine and wound were unrevealing. The blisters were disinfected with Octenisept $(0.1 \mathrm{~g}$ octenidindihydrochlorid, $2.0 \mathrm{~g}$ phenoxyethanol per $100 \mathrm{ml}$ ), and covered with Acticoat $^{\mathrm{TM}}$ (silver antibacterial protection; Smith\&Nephew, London, United Kingdom) and dry sterile gauzes. The patient remained conscious and vitally stable throughout the inpatient course. Dressings with Acticoat were changes every 3 days (fig. 2). The patient continued to have intermittent high fever up to $40^{\circ} \mathrm{C}$. Since all bacterial and fungal screenings remained negative, the focus of infection was unclear. Upon consultation with the infectious disease service, empiric antibiotic and antifungal medications were started with Avalox $(400 \mathrm{mg}$ moxifloxacin i.v., 1 per day) and Ecalta (100 mg anidulafungin i.v., 1 per day). The former anti-viral HIV therapy was continued without changes.

Three days after admission to the hospital, polymerase chain reaction testing for viruses revealed DNA in serum of dengue virus. The patient had initially denied any recent travel, but after further questioning she admitted a recent visit to Kenya. Antimicrobials were stopped and fever began to decrease slowly on the fifth day of inpatient treatment. Wounds recovered well under careful treatment 
with Acticoat. After 18 days of inpatient treatment, the patient was able to be discharged home. Followup examination in our outpatient center revealed no secondary deficits.

\section{Discussion}

The cutaneous findings of TEN result in acute macular erythematous rash with bulla, and red macules with central blistering [4]. Usually, the lesions rapidly exhibit the Nikolsky's sign (epidermal separation induced by gentle lateral pressure of the skin surface) which facilitates the diagnosis [5]. Besides affecting the mucosal and ocular surface, the lesions can become extremely extensive until a complete loss of epidermis within $24 \mathrm{~h}$. Thus, TEN is associated with significant morbidity, including thermoregulatory disturbance and dehydration, and leads to lung, renal, liver and heart failure in severe cases [6]. Mortality is approximately $40 \%$, but it depends on co-morbidity and individual factors [7]. The risk of mortality can be assessed by a specific severity evaluation system, also known as the Severity-of-Illness Score for Toxic Epidermal Necrolysis or SCORTEN [6]. In our specific case the SCORTEN score was calculated to be two.

In the majority of the cases a drug reaction is the cause of TEN. Most commonly involved are several antibiotics (sulfonamide, tetracycline, quinolones, $\beta$-lactam), anticonvulsants (phenytoin, carbamazepine), nonsteroidal anti-inflammatory drugs or alluporinol [4]. To date, research has failed to demonstrate the mechanism by which exposure to a particular drug can lead to TEN pathology. Alternately, a combination of different drugs rather than a single drug may be the possible cause [4].

In the presented case, however, we presume that the TEN was a reaction to cefuroxime, azithromycin or the combination of both medications prescribed by the general practitioner.

But besides drugs, certain individuals have an enhanced risk for TEN. This includes bone marrow transplant patients [8], individuals with systemic lupus erythematosus, only rarely persons with exposure to certain chemicals [9], and individuals receiving different vaccinations [4] as well as persons with HIV-1 infection [10]. In our case, the patient was HIV positive, which could contribute to the occurrence of TEN. However, the possible involvement and contribution of an infection with the dengue virus and resulting DF is unknown.

Transmitted by the Aedes aegypti mosquito, DF is a disease belonging to the family Flaviviridae, genus Flavivirus [11]. DF, as well as the more severe dengue hemorrhagic fever, is caused by four closely related viruses called dengue 1 through 4 (DENV 1-4) [12]. Dengue viruses are maintained in primitive rainforest cycles involving lower primates and mosquitoes in Asia and West Africa [13]. However, DEN viruses can be transmitted in an urban cycle between humans and the highly domesticated mosquito [14]. Indeed, the A. aegypti proves to be a very efficient epidemic vector as DEN viruses are the only arboviruses that have fully adapted to humans and are maintained in large urban centers of the tropics [15]. Dengue virus infection in humans can cause a spectrum of illness ranging from occult infection to severe hemorrhagic disease [15]. Fortunately, the percentage of fatal cases is about only $5 \%$, thus the majority of infections present an abrupt onset of mild febrile illness [15], which applies well to our presented case. 
However, because of the risk of a hemorrhagic fever, these patients have to be monitored carefully.

DF is a very old disease and has historically caused major public health problems due to wide epidemics during its starting period in the 17th until the early 20th century [14]. The initial geographic expansion of DF was closely tied to the global spread of $A$. aegypti mosquitoes from Africa to other parts, but always remained in tropical regions [16]. Thus, infection in humans in temperate zones such as Europe is usually acquired by exposure to mosquitoes in equivalent tropical regions. Although the diagnosis of DF in Europe is rare, it should be taken under consideration amongst febrile returning travelers.

Intriguingly, in the past 30 years the DEN viruses have spread between countries and continents in the tropical regions [15], which increased its frequency in the Pacific Islands, South America and Asia. But still, the infection of DEN virus is limited to tropical regions with occurrence of $A$. aegypti, and thus making its appearance in temperate zones very rare.

However, this case report not only presents the illness of TEN, but it demonstrates that staff in specialized centers has to be well aware of improbable findings as, for example, an uncommon virus infection.

Thus, it is important that treatment of TEN always includes an interdisciplinary approach involving dermatologists, ophthalmologists, intensive care physicians, burn specialists, and beyond this, various other departments. To the best of our knowledge, we present for the first time a case of TEN with DF in a European ICU. We emphasize that TEN can be a complex and diverse illness resulting in total organ failure and shock in severe cases, and it is always challenging for an intensive care team, especially if rare pathological findings occur.

\section{Acknowledgements}

We want to thank Richard Bucala and Jürgen Bernhagen for their assistance in this interdisciplinary collaboration. G.G. was supported by the 'START'-program of the RWTH Aachen University, Aachen, Germany, and travel funds from the Deutsche Forschungsgemeinschaft (DFG) (GR 3724/1-1).

\section{Disclosure Statement}

All authors declare no conflict of interest. 


\begin{tabular}{c|l|l|l}
$\begin{array}{c}\text { Case Reports in } \\
\text { Demillatology }\end{array}$ & $\begin{array}{l}\text { Case Rep Dermatol 2010;2:189-194 } \\
\text { DOI: 10.1159/000322963 }\end{array}$ & $\begin{array}{l}\text { Published online: } \\
\text { December 7, 2010 }\end{array}$ & $\begin{array}{l}\text { O 2010 S. Karger AG, Basel } \\
\text { ISSN 1662-6567 } \\
\text { www.karger.com/cde }\end{array}$ \\
\hline
\end{tabular}

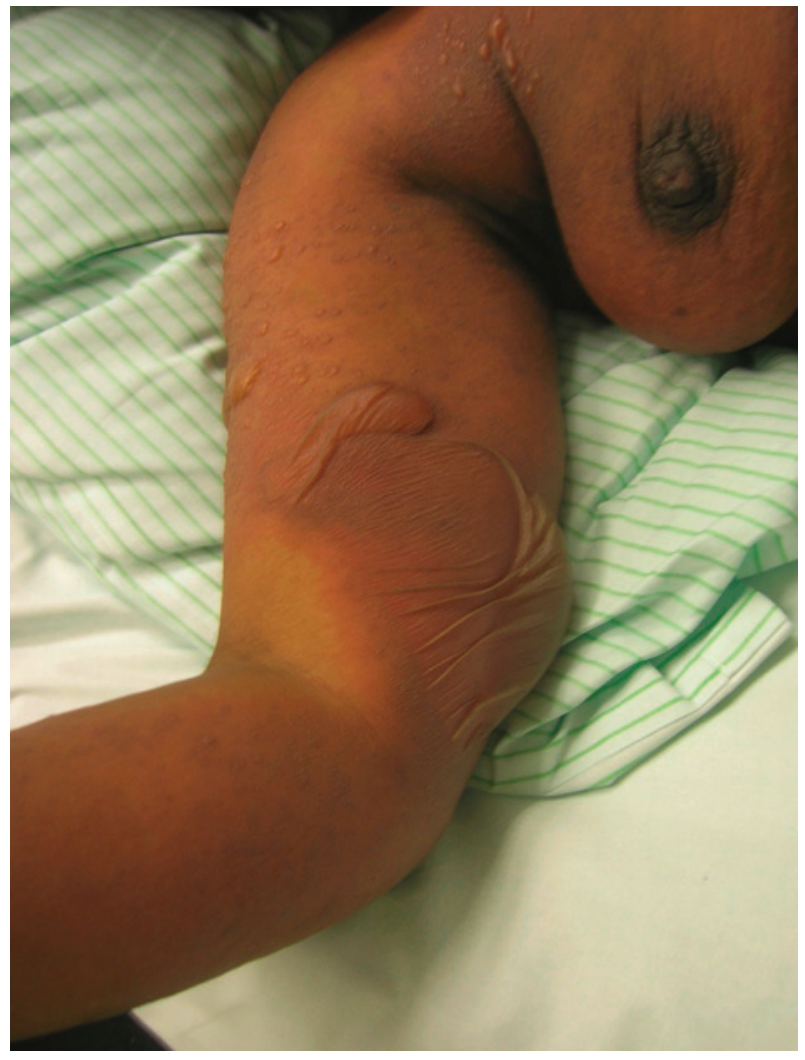

Fig. 1. Typical blisters observed on admission (right arm).

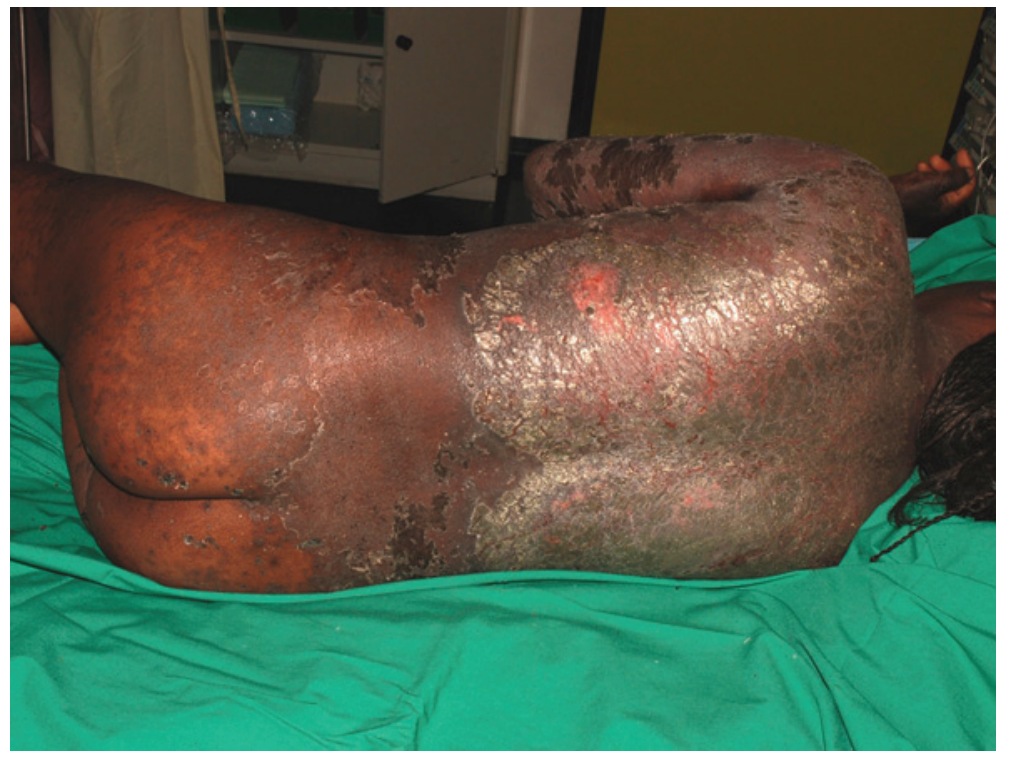

Fig. 2. Progressive wound healing during treatment with Acticoat ${ }^{\mathrm{TM}}$. 


\section{References}

1 Lyell A: Toxic epidermal necrolysis: an eruption resembling scalding of the skin. Br J Dermatol 1956;68:355361.

2 Roujeau JC, Guillaume JC, Fabre JP, Penso D, Flechet ML, Girre JP: Toxic epidermal necrolysis (Lyell syndrome). Incidence and drug etiology in France, 1981-1985. Arch Dermatol 1990;126:37-42.

3 Boorboor P, Vogt PM, Bechara FG, Alkandari Q, Aust M, Gohritz A, et al: Toxic epidermal necrolysis: use of Biobrane or skin coverage reduces pain, improves mobilisation and decreases infection in elderly patients. Burns 2008;34:487-492.

4 Lissia M, Mulas P, Bulla A, Rubino C: Toxic epidermal necrolysis (Lyell's disease). Burns 2009; in press, doi: 10.1016/j.burns.2009.06.213.

5 Goodman H: Nikolsky sign; page from notable contributors to the knowledge of dermatology. AMA Arch Derm and Syphilol 1953;68:334-335.

6 Bastuji-Garin S, Fouchard N, Bertocchi M, Roujeau JC, Revuz J, Wolkenstein P: SCORTEN: a severity-ofillness score for toxic epidermal necrolysis. J Invest Dermatol 2000;115:149-153.

7 Mockenhaupt M, Messenheimer J, Tennis P, Schlingmann J: Risk of Stevens-Johnson syndrome and toxic epidermal necrolysis in new users of antiepileptics. Neurology 2005;64:1134-1138.

8 Villada G, Roujeau JC, Cordonnier C, Bagot M, Kuentz M, Wechsler J, et al: Toxic epidermal necrolysis after bone marrow transplantation: study of nine cases. J Am Acad Dermatol 1990;23(5 Pt 1):870-875.

9 House RA, Jakubovic H, Wong L, Holness DL: Work-related toxic epidermal necrolysis? J Occup Med 1992;34:135-139.

10 Saiag P, Caumes E, Chosidow O, Revuz J, Roujeau JC: Drug-induced toxic epidermal necrolysis (Lyell syndrome) in patients infected with the human immunodeficiency virus. J Am Acad Dermatol 1992;26:567574 .

11 Monath TP, Heinz FZ: Flaviviruses; in Fields BN KD, Howley PM (eds): Fields virology. 3rd ed. Philadelphia: Lippincott Raven Publishers 1996, pp 961-1034.

12 Rigau-Pérez JG, Gubler DJ, Vorndam AV, Clark GG: Dengue: A Literature Review and Case Study of Travelers from the United States, 1986-1994. J Travel Med 1997;4:65-71.

13 Rudnick A, Lim TW: Dengue fever studies in Malaysia. Bulletin from the institute for medical research. Malaysia 1986;23:1-241.

14 Soper FL, Penna HA, Cardoso E, Serafin J, Frobisher M, Pinheiro J: Yellow fever without Aedes aegypti: study of a rural epidemic in the Valle do Chanaan, Espirito Santo, Brazil. Am J Trop Med Hyg 1932;18:555-587.

15 Gubler DJ: Dengue and dengue hemorrhagic fever. Clin Microbiol Rev 1998;11:480-496.

16 Gubler DJ: The global pandemic of dengue/dengue haemorrhagic fever: current status and prospects for the future. Annals of the Academy of Medicine, Singapore 1998;27:227-234. 